\title{
FFHMT 2020
}

PROCEEDINGS OF THE $7^{\text {TH }}$

INTERNATIONAL CONFERENCE ON FLUID

FLOW, HEAT AND MASS TRANSFER (FFHMT'19)

November 15, 2020 - November 17, 2020 | Niagara Falls, Canada| Virtual Conference

(@) COPYRIGHT 2020, INTERNATIONAL ASET INC. - ALL RIGHTS RESERVED. ISBN: 978-1-927877-59-3 | ISSN: 2369-3029 


\section{TABLE OF CONTENTS}

Welcome Message from the Conference Chair............................... 3

About FFHMT'20.................................................... 4

Scientific Committee...................................................... 5

Keynote Speakers.................................................... 6

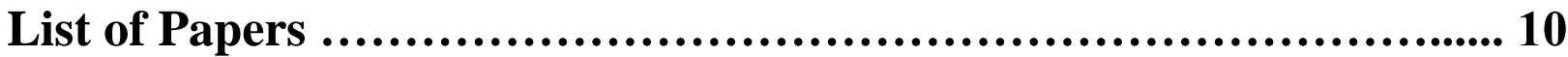

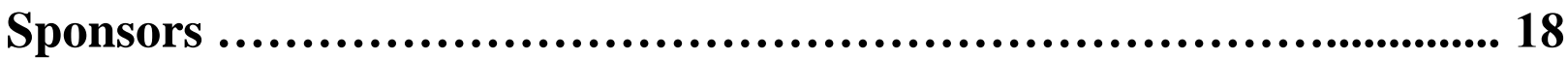

Journal Special Issue......................................................... 19

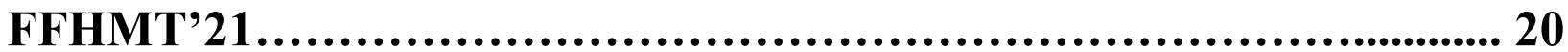

Ethics \& Malpractice ....................................................... 21

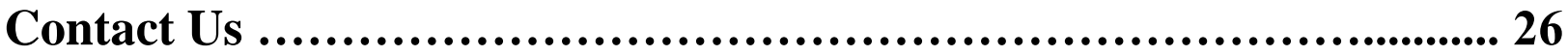




\section{WELCOME MESSAGE FROM THE CONFERENCE CHAIR}

On behalf of the International Academy of Science, Engineering and Technology (International ASET Inc.), the organizing committee would like to welcome you to the $7^{\text {th }}$ International Conference of Fluid Flow, Heat and Mass Transfer (FFHMT'20).

FFHMT'20 is aimed to become one of the leading international annual conferences in the fields of heat, momentum, and mass transfer. This conference will provide excellent opportunities to the scientists, researchers, industrial engineers, and university students to present their research achievements and to develop new collaborations and partnerships with experts in the field.

FFHMT'20 is a series of international conferences which are held yearly. These conferences focus on all aspects of fluid flow, heat and mass transfer. After the success of the fifth conference in Niagara Falls, Canada, FFHMT will remain in Canada and will host the sixth international conference.

In the Sixth meeting of this conference, three keynote speakers will share their expertise with the aim of exposing participants to a wide spectrum of applications, and to foster crosspollination of ideas and develop new research interests. In addition, approximately 40 papers will be presented from professors, students, and researchers across the world.

We thank you for your participation and contribution to the $7^{\text {th }}$ International Conference of Fluid Flow, Heat and Mass Transfer (FFHMT'20). We wish you a very successful and enjoyable experience.

\section{Dr. Boguslaw Kruczek}

Conference Chair and Proceedings Editor FFHMT'20

\section{Dr. Xianshe Feng}

Conference Co-Chair and Proceedings Editor FFHMT'20

Dr. Wael H. Ahmed

Technical Program Chair

FFHMT'20 


\section{ABOUT FFHMT'20}

The International Conference on Fluid Flow, Heat and Mass Transfer (FFHMT) aims to become the leading annual conference in fields related to traditional and modern transport phenomena. The goal of FFHMT'20 is to gather scholars from all over the world to present advances in the fields of transport phenomena and to foster an environment conducive to exchanging ideas and information. This conference will also provide an ideal environment to develop new collaborations and meet experts on the fundamentals, applications, and products of the mentioned fields.

FFHMT is a series of international conferences held yearly. These conferences focus on all aspects of fluid flow, heat, and mass transfer. After successfully holding FFHMT'14 to FFHMT'19 in Canada, FFHMT'20 is hosted in Canada as well this year.

FFHMT is an acronym for Fluid, Flow, Heat, and Mass Transfer.

The proceedings is published in Ottawa, Canada.

All papers were peer-reviewed

The congress proceedings is published under an ISSN and ISBN number

Each paper is assigned a unique DOI number by Crossref

The conference proceedings is indexed by $\underline{\text { Scopus and Google Scholar }}$

The proceedings is permanently archived in Portico (one of the largest community-supported digital archives in the world)

\section{Google Scholar}

Return to Top 


\section{SCIENTIFIC COMMITTEE}

We would like to thank the following for accepting to act as a member of the Scientific Committee for the FFHMT'20 Conference:

Scientific Committee Chairs

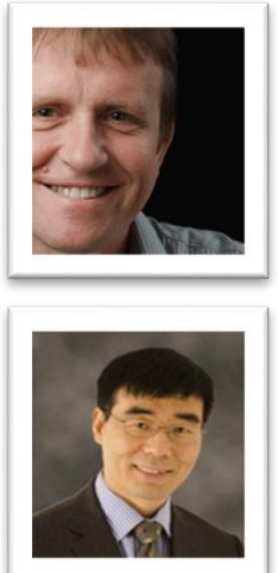

Dr. Boguslaw Kruczek

University of Ottawa, Canada

Conference Chair

\section{Scientific Committee Members}

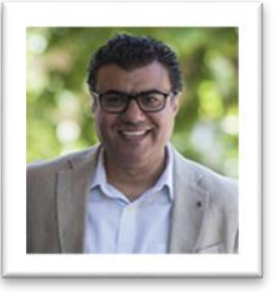

Dr. Wael H. Ahmed University of Guelp, Canada

Technical Program Chair

Dr. Sanjeev Chandra, University of Toronto, Canada

Dr. Yan Chen, Purdue University, USA

Dr. Yusuf Chisti, Massey University, New Zealand

Dr. Mostafa Elshaqawy, University of Guelph, Canada

Dr. Wagdi G. Habashi, McGill University, Canada

Dr. Huan-Jang Keh, National Taiwan University, Taiwan

Dr. Nikolai Kozlov, Institute of Continuous Media Mechanics UrB RAS, Russia

Dr. Krishnaswamy Nandakumar, Louisiana State University, USA

Dr. Wenxiao Pan, University of Wisconsin-Madison, USA

Dr. Bertrand Rollin, Embry-Riddle Aeronautical University, USA

Dr. Gary Rosengarten, RMIT University, Australia

Dr. Gerry Schneider, University of Waterloo, Canada

Dr. Saeed Tiari, Gannon University, USA

Dr. Lian Shen, University of Minnesota, USA

Dr. Jules Thibault, University of Ottawa, Canada

Dr. Velisa Vesovic, Imperial College London, UK

Dr. Qian Xue, University of Maine, USA

Dr. Sinan Yapici, Inonu University, Turkey 


\section{KEYNOTE SPEAKERS}

The keynote information for the 7th International Conference of Fluid Flow, Heat and Mass Transfer (FFHMT'20) is as follows:

\section{Plenary Speakers}

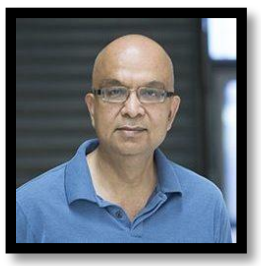

Dr. Sanjeev Chandra University of Toronto, Canada Plenary Speaker

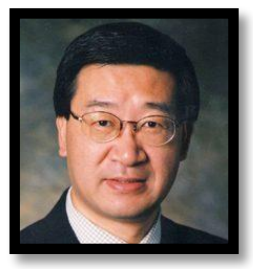

Dr. Dayong Gao

University of Washington, USA Plenary Speaker

\section{Keynote Speaker}

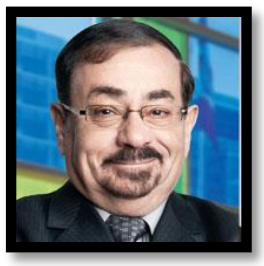

Dr. Wagdi G. Habashi

McGill University, Canada

Keynote Speaker 


\section{FFHMT'20 PLENARY SPEAKER}

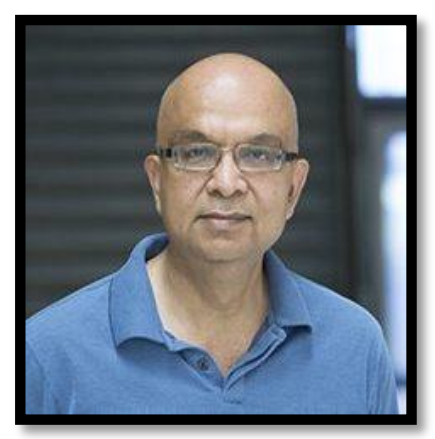

\section{Titles: Application and Drying of}

Automotive Paints

Dr. Sanjeev Chandra, University of Toronto,

Canada

\section{View Abstract}

\section{Return to Top}

Sanjeev Chandra is a Professor in the Department of Mechanical and Industrial Engineering at the University of Toronto, which he joined in 1990 . He received his B. Tech. from the Indian Institute of Technology, Kanpur (1981) his MS from Vanderbilt University (1983) and Ph.D. from Cornell University (1990). He has served as the Associate Chair (undergraduate studies), Associate Chair (graduate studies), Vice-Chair and Acting Chair of the MIE department, and Acting Vice-Dean (undergraduate studies) of the Faculty of Applied Science and Engineering.

Prof. Chandra is known internationally for his research on the dynamics of droplets and sprays and is one of the founders of the Centre for Advanced Coating Technologies at the University of Toronto. His research spans the areas of fluid mechanics, heat transfer and materials science and has also been applied in spray coating, spray cooling, spray painting, ink-jet printing, electronic cooling and waste heat recovery. Prof. Chandra has published over 200 papers in referred journals and international conference proceedings. He teaches courses in thermodynamics and heat transfer and has served as visiting professor at the University of Limoges (France) Korea University (S. Korea), the University of Bremen (Germany), the University of Darmstadt (Germany), Nanyang Technical University (Singapore) and the University of Brighton (UK). He has written an undergraduate textbook on thermodynamics and several chapters for books on the subjects of thermal spray coating, heat transfer and sprays. In 2010 he was awarded the The Brockhouse Canada Prize for Interdisciplinary Research, awarded by the Natural Sciences and Engineering Research Council of Canada to recognize outstanding collaborative research. In 2015 he was awarded the Jules Stachiewicz Medal by the Canadian Society for Mechanical Engineering for outstanding contributions to heat transfer. He is a Fellow of the Canadian Academy of Engineering, the American Society of Mechanical Engineers, the Canadian Society for Mechanical Engineering and the American Association for the Advancement of Science. 


\section{FFHMT'20 PLENARY SPEAKER}

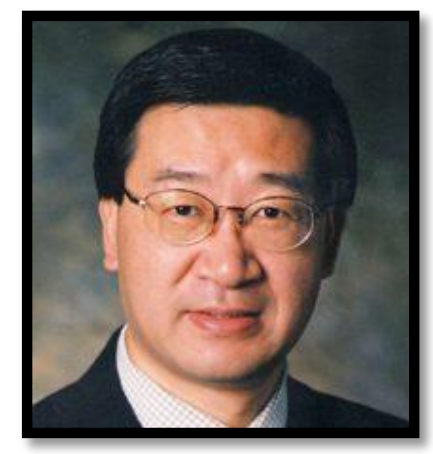

Titles: Freezing of Living Cells and Organs: A Great Challenge for Thermal Science and Technology Dr. Dayong Gao, University of Washington, USA

\section{View Abstract}

\section{Return to Top}

Dr. Dayong Gao is Origincell Endowed Professor in Department of Mechanical Engineering and Director of Center for Cryo-Biomedical Engineering and Artificial Organs, University of Washington, Seattle, WA, USA. Prior to joining University of Washington, he was a Professor, Alumni Endowed Professor, and Baxter Healthcare Corp Chair of Mechanical Engineering at University of Kentucky, Lexington, KY, USA.

Dr. Gao's major research has been focusing on the following bio-mechanical engineering areas for the past 30 years: (1) cryogenic engineering and cryobiology: revealing the fundamental mechanisms of cryoinjury and cryoprotection to living biological systems at low temperatures, and developing optimal methods and novel technology for long-term cryopreservation and biobanking of living cells, tissues, and organs for use in cellular therapy, tissue engineering, regenerative medicine, new drug development, organ transplantation, and bio-conservation of endangered species, etc. (2) artificial kidney and liver systems, for the life-saving treatment of end-stage kidney and liver failure; and (3) bio-instruments and micro-sensors (BioMEMS) for rapid and cost-effective diagnosis of diseases with high sensitivity and specificity. His research work has been supported by awards and grants from National Institutes of Health (NIH), National Science Foundation, National Cancer Society, American Heart Association, Bill and Melinda Gates Foundation, Whitaker Foundation, Washington Research Foundation, and industrial companies.

For more information Please Visit:

https://ffhmt.com/program/ 


\section{FFHMT'20 KEYNOTE SPEAKER}

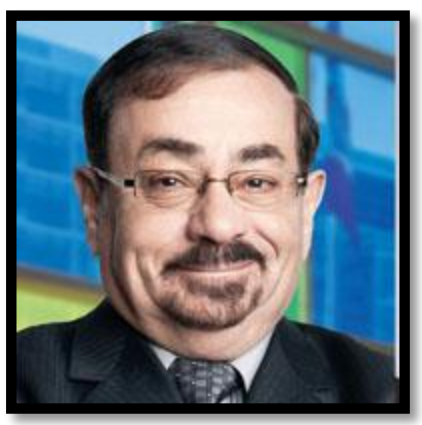

Titles: Reduced Order Modeling is the Road to Faster and Safer In-Flight Icing Certification Dr. Wagdi G. Habashi, McGill University, Canada

\section{View Abstract}

\section{Return to Top}

Wagdi Habashi is a Professor in the Mechanical Engineering Department of McGill University and directs its Computational Fluid Dynamics Laboratory. He has held, for the last 19 years, 3 successive NSERC Industrial Research Chairs with Bombardier (aircraft), Bell (helicopters), CAE (simulators) and Lockheed Martin (hypersonic transport).

Professor Habashi holds a PhD in Aeronautical Engineering from Cornell and has been active for 40 years with Aerospace OEMs internationally, with close to 400 publications, at least one third of them with industry.

Dr. Habashi established Newmerical Technologies International (NTI), developer of the FENSAP-ICE In-Flight Icing Simulation System currently used in 24 countries. NTI was acquired by ANSYS in 2015. Following this, Professor Habashi started CERTIF-ICE, a one-stop-shop for in-flight icing certification, responsible for the successful natural icing campaigns, in Canada, of COMAC's ARJ21 (turbofan) and AVIC's Y-12F (turboprop).

Habashi is a Knight of the Order of Québec, a Fellow of the Academy of Sciences of the Royal Society of Canada, of the Canadian Academy of Engineering, of the American Institute of Aeronautics and Astronautics, of the American Society of Mechanical Engineers and of Pratt \& Whitney Canada. He is the recipient of a multitude of scientific and industrial awards among them the Steacie, Killam, Floyd, McCurdy and several others. 


\section{LIST OF PAPERS}

The following papers were presented at the 7th International

Conference on Fluid Flow, Heat and Mass Transfer (FFHMT'20).

\section{Flow, Heat and Mass Transfer Devices}

Title: Experimental Investigation of Humidification Efficiency of a Structured Packing-Based Counter Flow Humidification System

Authors: Sampath Suranjan Salins, S V Kota Reddy, Shivakumar

\section{View Paper}

Title: Enhanced Water Molecule Diffusion in Direct Air Electrodialysis Membrane-based Dehumidification System

Authors: Muxing Zhang, Xiaosong Zhang, Kwok Wei Shah

\section{View Paper}

Title: Heat Transfer by a Briefcase-shaped Air Cooler Using Thermoelectric Cooling Technology: A Case Study

Authors: Abu Raihan Mohammad Siddique, Syed Tabeeb Wasit Bin Hasan, Mohammad Reza Mohaghegh, Shaikh Hasibul Majid, Shohel Mahmud

\section{View Paper}

Title: Influence of Plate Geometry on Sensible Effectiveness of Fixed-Bed Regenerators

Authors: Easwaran N. Krishnan, Hadi Ramin, Gurubalan Annadurai, Carey J. Simonson

\section{View Paper}




\section{LIST OF PAPERS}

\section{Flow, Heat and Mass Transfer Devices}

Title: Parametric Analysis for Varying Packing Materials \& Water Temperatures in a Humidifier

Authors: Sampath Suranjan Salins, Shahida A Siddiqui, S.V. Kota Reddy, Shiva Kumar

\section{View Paper}

Title: Water Suspension Infiltration with Adsorption Including Heat Transport in Unsaturated-Saturated Porous Media Authors: Jozef Kačur, Patrik Mihala

\section{View Paper}




\section{LIST OF PAPERS}

\section{CDF}

Title: Numerical Investigation of Turbulent Flow inside a Cubical Cavity with Heat Transfer from the Top

Authors: Vitaly Haslavsky, Helena Vitoshkin

\section{View Paper}

Title: Experimental and Numerical Study of a Latent Heat Thermal Energy Storage System Enhanced with Fins

Authors: Saeed Tiari, Addison Hockins, Samantha Moretti

\section{View Paper}

Title: Numerical Study of the Cavitating Flow through a Venturi Section by Means of OpenFOAM and Gmsh Tool

Authors: Víctor Hidalgo, Gisell Suárez, Jose Erazo, Diana Puga, David Marquez, Ignacio Benavides, Esteban Valencia, XianWu Luo

\section{View Paper}

Title: CFD Simulation of Flow Maldistribution due to Blockage in Microstructured Heat Exchanger

Authors: Sahba Sadir, Christoph Spiegel, Wolfgang Augustin, Stephan Scholl, Manfred Kraut

\section{View Paper}




\section{LIST OF PAPERS}

\section{CDF}

Title: Modeling Combustion and Heat Transfer in a Single-Element GCH4/GOX Rocket Combustor

Authors: Christof Roth, Nikolaos Perakis, Oskar J. Haidn

\section{View Paper}

Title: Numerical Analysis for Cavitation flow of the Depressurization Orifice of an Auxilary Feedwater Pump

Authors: Juneho Bae, Gong-Hee Lee

\section{View Paper}

Title: Acoustic-driven Oscillations of a Bubble in a Narrow Gap Authors: Jacqueline Mifsud, Duncan A. Lockerby, Yongmann M. Chung, Gordon Jones

\section{View Paper}




\section{LIST OF PAPERS}

\section{Two and Multiphase Flow and Heat Transfer}

Title: Effect of Multiple Water Impinging Jet Array on Quenching Hot Rotary Hollow Cylinders

Authors: Mohammad Jahedi, Bahram Moshfegh

\section{View Paper}

Title: Prediction of Two-Phase Flow Patterns Using Machine Learning Algorithms Authors: Naief Almalki, Wael H. Ahmed

\section{View Paper}

Title: Design Algorithm Evaluation of Swirler-Injector Systems in LiquidBurning Combustion Chambers

Authors: Arash Mousemi, Sepehr Mosadegh, Alireza Khademi, Giancarlo Sorrentino

\section{View Paper}

Title: Comparative Study for Prediction Accuracy of RANS Turbulence Models: Multi-Phase Flow in the Cavitating Venturi

Authors: Gong-Hee Lee

\section{View Paper}

Title: Development of Trend Map on the Departure from Nucleate Boiling Ratio in Non-Loss of Coolant Accidents of Nuclear Power Plant

Authors: II S. Lee, Kyung L. Baek, Kwang W. Seul, Yong C. Kim

\section{View Paper}




\section{LIST OF PAPERS}

\section{Numerical Flow and Heat Transfer}

Title: Thermal Simulation of Big Area Additive Manufacturing

Authors: Brian Friedrich, Kyosung Choo

\section{View Paper}

Title: Simulation of a Research Data Centre Room in an Academic Campus

Authors: Khaled Alsharif, Kyosung Choo

\section{View Paper}

Title: Parallel Finite Element Approach for large Thermal Problems Applied to Glass Bending Furnace

Authors: Marc Baydoun

\section{View Paper}




\section{LIST OF PAPERS}

\section{Analytical Solution of Conservation Equations}

Title: Single-Phase Natural Circulation in a PWR during a Loss of Coolant Accident

Authors: Mohammed W. Abdulrahman, Mikdam M. Saleh, Jonathan Anand

\section{View Paper}

Title: A New Correlation for the Onset of Nucleate Boiling Heat Flux under an Impinging Planar Water Jet Authors: Mohammad Reza Mohaghegh, Abu Raihan Mohammad Siddique, Shohel Mahmud, Syeda Tasnim

\section{View Paper}

Title: Natural Circulation in a Pressurized Water Reactor with a Combined Single and Two-Phase Mode Authors: Mohammed W. Abdulrahman, Mikdam M. Saleh, Jonathan Anand

\section{View Paper}

Title: Two-Phase Flow in the Natural Circulation of a Pressurized Water Reactor

Authors: Mohammad W. Abdulrahman, Mikdam M. Saleh

\section{View Paper}




\section{LIST OF PAPERS}

\section{Experimental Fluid Flow and Heat Transfer}

Title: Experimental Study of the Ventilation Arrangement's Effect on Particle Concentration in a Surgery Room

Authors: Ali Parcheforosh, Arash Mousemi, Sorour A. Alotaibi, Alireza Khademi

\section{View Paper}

Title: The Turbulent/Non-Turbulent Interface Characteristics in an Axisymmetric Jet Authors: Khashayar F. Kohan, Susan Gaskin

\section{View Paper}

Title: Effect Of Ambient Turbulence On The Evolution And Mixing Of Passive Scalar In Turbulent Jet

Authors: Rana Sahebjam, Susan Gaskin

\section{View Paper}

Title: Experimental Investigation of Flat Fan Spray with Solid Impurities Authors: Zhaobo Li, Cheng Li

\section{View Paper}

Title: Temporal Flow Evolution On A Pediatric Ventricular Assist Device Authors: Vítor Augusto Andreghetto Bortolin, Bernardo Luiz Harry Diniz Lemos, Rodrigo de Lima Amaral, Simão Bacht, Marcelo Mazzeto, Idágene Aparecida Cestari, Júlio Romano Maneghini

\section{View Paper}

Title: Application of Deep Learning Convolutional Neural Network for Spray Characterization

Authors: Amin Heyrani Nobari, Farzaam Khorasani-Gerdehkouhi, Naib Gulam, NasserAshgriz

\section{View Paper}




\section{SPONSORS}

International ASET Inc. would like to thank the following sponsors for their support of FFHMT'20:
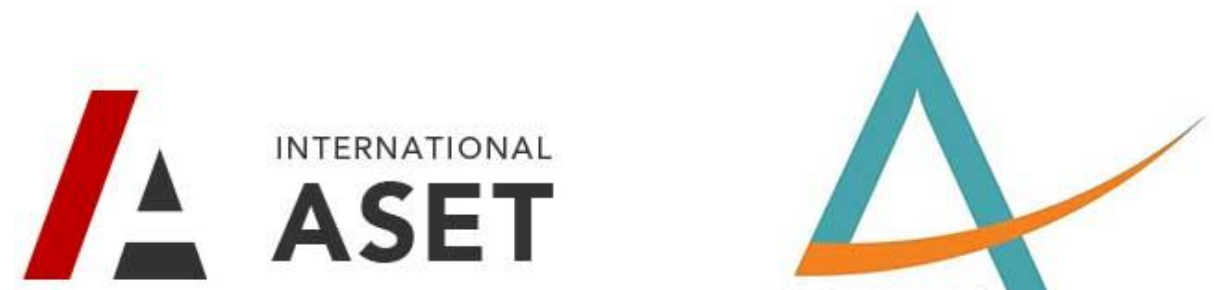

AVESTIA

\section{WHERE (2) SUBMIT}




\section{JOURNAL SPECIAL ISSUES}

Selected articles from the conference will be published in the Journal of Fluid Flow, Heat and Mass Transfer (JFFHMT)

after a secondary review process.

The publication fee will be waived for papers that win the best paper award. Other attendees will receive a $25 \%$ discount towards the publication fee of the journal.

This journal has adopted to the open-access model, meaning all free access to the journal's articles and content with no need for subscription. This ensures larger audience and therefore higher citations.

Users are allowed to read, download, copy, distribute, print, search, or link to the full texts of the articles in this journal without asking prior permission from the publisher or the author. This is in accordance with the BOAI defi nition of open access.

All published papers of JFFHMT will be submitted to Google Scholar, Microsoft Academic Search, Open J-Gate, Mendeley, Index Copernicus International, Academic Index, Mendeley, Primo Central, and Genomics JournalSeek for possible indexing. Additionally, they will be permanently archived in Portico (one of the largest community-supported digital archives in the world) and will be assigned unique DOIs. 


\section{FFHMT'21}

The $8^{\text {th }}$ International Conference of Fluid Flow, Heat and Mass Transfer (FFHMT'21) will be held on May 21 - 23, 2021 in Niagara Falls, Canada.

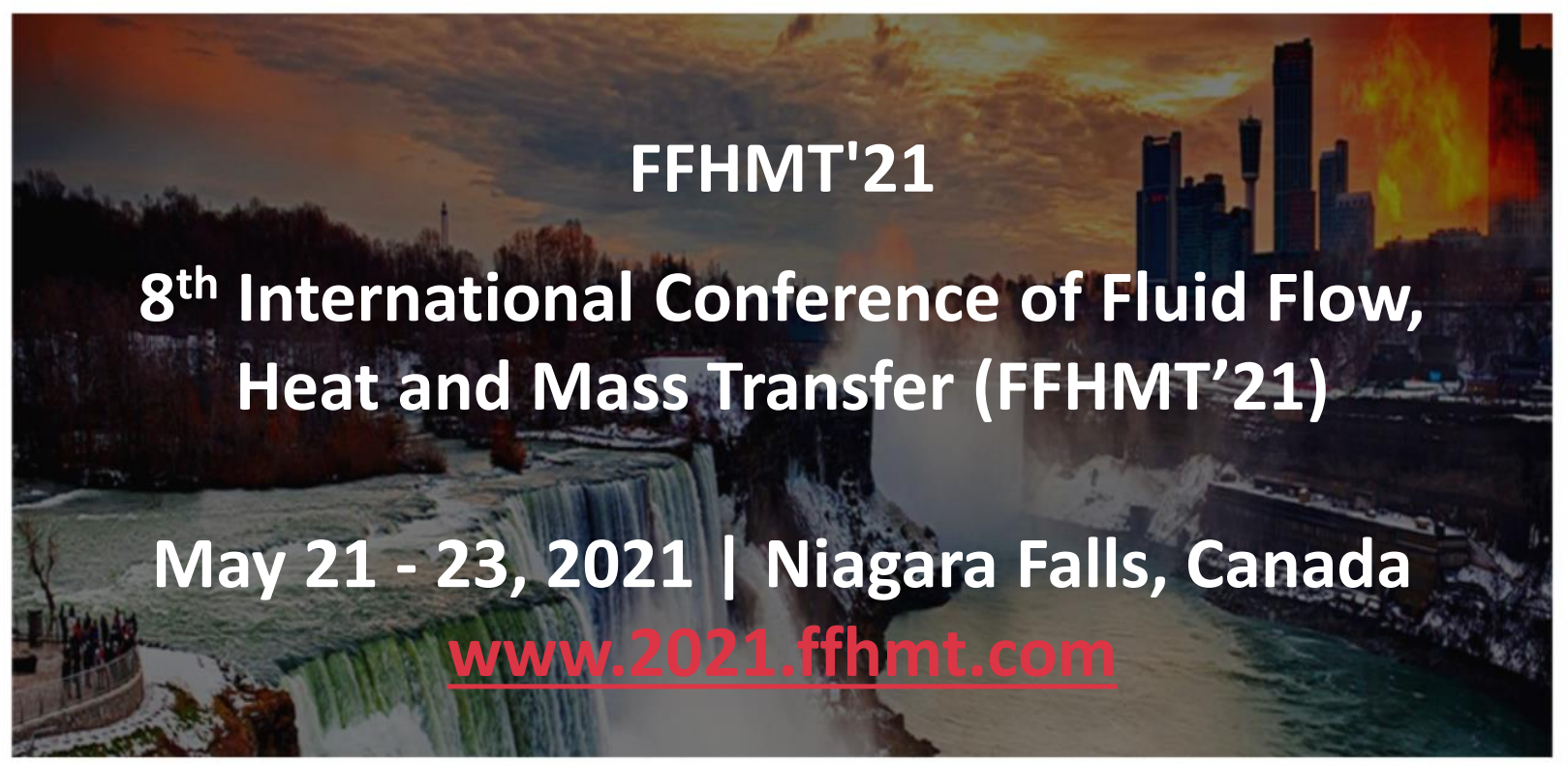

For inquiries and to obtain further information on the congress, please visit the website or call us at:

$+1-613-834-9999$

\section{Return to Top}




\section{ETHICS \& MALPRACTICE}

\section{Publication Ethics and Publication Malpractice Statement}

The following statement is mainly based on the Code of Conduct and BestPractice Guidelines for Journal Editors (Committee on Publication Ethics, 2011).

\section{Scientific Committee}

\section{Scientific Committee}

Scientific committees consisting of experts in the fields are established. The committees oversee the peer-review and publication process. To see the scientific committee members, please follow the link below.

\section{Scientific Committee}

\section{Equality and Decisions}

One or more reviewer, scientific committee member, or chair, (internal or external), are responsible for evaluating the relevance of the submitted manuscripts to the proceedings, technical and scientific merit, originally, and impact. These evaluations are to be carried out regardless of ethnicity, religion, gender, sexual orientation, political beliefs, and institutions. Successive to peer-review, the Chair has full authority and is solely responsible for the published content and the process thereof.

\section{Confidentiality}

Scientific committee member(s) and publishing staff may not disclose manuscripts or their content, directly or indirectly, to anyone other than individuals invited to review the manuscript (whether they accept or not), other reviewers of the same publications, and publishing staff.

\section{Conflicts of Interest}

Scientific committee member(s) and publishing staff may not utilize the contents of submitted manuscripts whether accepted or rejected, directly or indirectly for their own research purposes without prior written consent by the authors. 


\section{ETHICS \& MALPRACTICE}

\section{Reviewers}

\section{Contribution to Decisions}

In order for final decisions to be made regarding acceptance or rejection of papers, we rely on peer-review. Peer-review is the process of experts in the field reading, understanding, and objectively commenting on submitted papers. Through peer-review, scholars give back to the academic and scientific community by helping the chair(s) make decisions regarding manuscripts.

\section{Promptness}

Reviewers should promptly notify the chair(s) if they are unable or unqualified to carry out their reviewing duties. Reviewers should do their best to provide the reviews to the chair(s) as promptly as possible, and within the designated time-frame.

\section{Confidentiality}

Reviewers must not share the contents of the manuscripts they receive for review, regardless of their decision to review or contents of the review, directly or indirectly, with anyone other than the person who has assigned the review.

\section{Fairness}

Reviewers should review manuscripts fairly and objectively, with supporting evidence or arguments, regardless of personal feelings or biases.

\section{Thoroughness}

Reviewers should thoroughly read, understand, and provide constructive feedback with the aim of improving the manuscript. Reviewers should aim to identify and report technical issues, irregularities, mistakes, missing citations, and similarity to other published work.

\section{Conflicts of Interest}

Invited reviewers should immediately inform the chair(s) in case of a conflict of interest based on competitive, collaborative, personal, family, and other relationships with the authors or people involved in the work. 


\section{ETHICS \& MALPRACTICE}

\section{Authors}

\section{Authorship}

Only persons who have significantly contributed to the work and the manuscript can be named authors on a paper. These contributions include the idea/concept, design, experiments, evaluation, analysis, drafting or revision of the manuscript, and others. Authors must all have agreed to be named as such and for the manuscript to be submitted. Anyone who has contributed based on the above, but the level of contribution is not significant, may appear in the acknowledgement section of the manuscript.

\section{Accuracy, Originality, and Plagiarism}

Authors should describe their work and the results of their work accurately and in full. The level of provided accuracy and detail should be such that a reader can replicate the work independently. Inaccurate, incomplete, fraudulent, and misleading statements are considered unacceptable and unethical. Direct or indirect use of other people's work is not allowed, unless properly cited. Previous works that have influenced the current work should also be cited. Presenting someone else's work as one's own is strictly prohibited and is considered plagiarism.

\section{Data and Material}

Authors are encouraged to share their data, software, or other sharable material online, provided copyright and ownership laws surrounding that particular project permit. Authors may also be asked to share such material with the chair(s), and/or reviewers, and must be willing to do so if asked.

\section{Dual Submissions}

Submitting a manuscript to more than one venue (conference, journal, etc) simultaneously is not allowed. Presenting previously published work to be considered as a new submission, without a significant new interpretation or analysis, is prohibited. 


\section{ETHICS \& MALPRACTICE}

\section{Conflicts of Interest}

Authors must notify the chair(s) at the time of submission, if any factor outside the scope of the research has influenced any step of the work and manuscript writing. Examples of such factors include but are not limited to funding, grants, advisory and consultancy, stock ownership, current or past employment, and memberships, among others. All funding sources should be disclosed in the manuscript.

\section{Animal and Human Subjects}

Works involving human and/or animal subjects must ensure that the work has abided by institutional guidelines, and pre-approved by required bodies. Moreover, consent must be acquired from participants, and privacy of subjects must be ensured. All of the above must be specified with clear statements in the manuscript.

\section{Hazardous Material}

It should clearly be identified in the manuscripts if the works have involved hazardous chemicals and material, or devices that can be harmful.

\section{Reporting of Mistakes, Errata, and Retractions}

If an author identifies a major error in a published paper, he/she must immediately identify the publisher. Regardless of whether a significant error is reported by the authors of the work or other readers, authors are obligated to take the necessary steps to correct the issue. It is decided on a case-by-case basis whether an erratum will be submitted to notify future readers of the error and correction, or whether the paper will be retracted.

Unethical/plagiarism issues mostly result in a retraction, while unintended mistakes will mostly result in the publication of an erratum. 


\section{ETHICS \& MALPRACTICE}

\section{Publisher}

\section{Errata and Retractions}

The publisher takes the necessary steps to prevent mistakes, academic and scientific misconduct, and unethical behavior, both intended and unintended. When mistakes are reported, the publisher works with chair(s) and authors to publish an erratum clarifying the issue. In cases where the mistakes are severe and significant, the paper might be retracted. If unethical behavior, plagiarism, academic and scientific misconduct, or other such activities are proven to have taken place by an author or authors, the publisher will retract the paper.

\section{Content and Archiving}

The publisher preserves and stores all content digitally on their own servers, as well as through partnering with Portico (Digital Preservation and Electronic Archiving Service).

\section{Copyright and Access}

The proceedings and related papers are all based on the open-access model, which means interested individuals and institutions can access the material for free.

Users are allowed to read, download, copy, distribute, print, search, or link to the full texts of the articles in this proceedings without asking prior permission from the publisher or the author. This is in accordance with the BOAl definition of open access.

\section{Ownership and Management}

This conference-proceedings is managed and operated by the International ASET (International Academy of Science, Engineering, and Technology) and Avestia Publishing (the publishing arm of ASET).

\section{Schedule}

This conference proceeding accompanies the conference, meaning a new proceedings will be published every year for the corresponding annual conference of this series. 


\section{CONTACT US}

For inquiries and to obtain further information on the conferences, please visit our website or call us at: +1-613-834-9999

\section{Return to Top}

